\title{
Flaw Tolerance of Metallic Glasses
}

Wen Chen ${ }^{\text {a }, ~ Z e ~ L i u ~}{ }^{*}$ a,b , Jittisa Ketkaew ${ }^{\text {a }}$, Rodrigo Miguel Ojeda Mota ${ }^{\text {a }}$, Sung-Hyun Kim ${ }^{\text {a }}$, Michael Power ${ }^{\mathrm{c}}$, William Samela ${ }^{\mathrm{d}}$, Jan Schroers ${ }^{\mathrm{a}, \mathrm{e}}{ }^{\dagger}$

${ }^{a}$ Department of Mechanical Engineering \& Materials Science, Yale University, New Haven, CT, 06511, USA

${ }^{\mathrm{b}}$ Department of Engineering mechanics, School of Civil Engineering, Wuhan University, Wuhan, 430000, China

${ }^{c}$ School of Engineering and Applied Science, Yale University

${ }^{\mathrm{d}}$ Department of Geology and Geophysics, Yale University

${ }^{\mathrm{e}}$ Center for Research on Interface Structures and Phenomena (CRISP), Yale University

* Corresponding author. Tel.:+1 857498 0956; fax: +1 2034326775.

E-mail address: ze.liu@whu.edu.cn (Z. Liu) or

${ }^{\dagger}$ Corresponding author. Tel.: +1 203432 4346; fax: +1 2034326775.

E-mail address: jan.schroers@yale.edu (J. Schroers) 


\begin{abstract}
The flaw tolerance of bulk metallic glasses (BMGs) is evaluated using a thermoplastic synthesis approach. We found that flaw tolerance quantified by the notch toughness decreases apparently with decreasing radius until a critical value. Below this critical value, measured notch toughness is independent of its radius, revealing a flaw tolerance behavior of BMGs. We explain such flaw tolerance by a critical plastic zone originating from the BMGs' inherent crack tip blunting capability. This zone defines a characteristic distance over which stable shear banding plastic process develops prior to fracture instability. The specific characteristic distance and crack blunting capability vary widely among BMGs, which rationalizes the vast variety in their fracture behavior and suggest specific flaw tolerance. Our finding is encouraging for BMGs' structural applications since flaws smaller than the critical value are increasingly difficult to avoid but are "indistinguishable" in their influence to fracture toughness.
\end{abstract}

Keywords: flaw tolerance; toughness; metallic glass; thermoplastic forming; mechanical behavior 


\section{Introduction}

Flaws are almost inevitably present in engineering structural materials. They originate from fabrication, mechanical damage, corrosion, or structural features such as microcracks, corners, holes, and welded joints. In general, structural flaws behave as stress risers and can exert a drastic effect on the materials' mechanical performance. For example, in brittle materials such as ceramics and oxide glasses, flaws in the form of pores and microcracks can dramatically degrade strength and toughness, and often cause premature brittle fracture at a stress well below their estimated yield strength [1]. As a consequence, most structural materials, particularly brittle ones are not limited by their strength but rather by their flaw resistance (or fracture toughness). Therefore, fracture toughness is often the limiting design consideration [2], and a fundamental understanding of the material's response to flaws is of great significance.

Most structural flaws can be represented as sphere-like defects with finite radii. Through introducing a notch crack into a bulk sample, notch toughness testing has been widely utilized to assess the flaw resistance in a wide range of materials [3-5]. In quantifying the notch toughness, $K_{Q}$, the notch radius, $\rho$, is a key parameter that defines the sharpness of the notch and hence simulates the stress concentration factor of a flaw. Variation of $\rho$ may affect stress field and crack propagation behavior. Influence of $\rho$ on notch toughness measurements has been widely studied in various materials classes such as crystalline metals, ceramics, and composites [6-11]. It has been found for some materials that $K_{Q}$ decreases with decreasing $\rho$ due to the elevation of stress intensification until a critical notch radius, $\rho_{c}$, is reached. Below $\rho_{c}, K_{Q}$ has been found to be independent of $\rho$, which means flaws smaller than $\rho_{c}$ are indistinguishable from $\rho_{c}$ [7-11]. This critical radius, which is essential for the use of corresponding materials in structural applications, has been associated with the material's specific microstructural features. For 
example, in crystalline metals or ceramics where grain boundaries often act as an effective barrier to crack propagation, $\rho_{c}$ is controlled by the grain size $[7,9]$. In composites, the value of $\rho_{c}$ has been associated with the spacing of secondary phases or inclusions $[10,11]$. More generally, microstructural features of a material have been associated with the fracture toughness or the flaw tolerance.

Lacking microstructural features, bulk metallic glasses (BMGs) are a class of amorphous structural alloys for which crystallization can be readily avoided during solidification [12]. Due to an isotropic and homogeneous structure, BMGs generally exhibit high strength and high elasticity [12-14]. Fracture toughness, on the other hand, ranges from ideally brittle to extraordinary tough within the material class of BMGs $[5,15]$. Precise measurements of BMGs' toughness have been proven challenging [16]. For example, toughness values ranging from $\sim 16$ to $\sim 130 \mathrm{MPa} \sqrt{\mathrm{m}}$ have been measured for $\mathrm{Zr}_{41.2} \mathrm{Ti}_{12.5} \mathrm{Cu}_{10} \mathrm{Ni}_{10} \mathrm{Be}_{22.5} \mathrm{BMG}$ [17-21]. It has been speculated that observed large scatter originates from the variety of sample geometries or loading modes [22-26], as well as difficulties in the sample preparation such as difficulties in fabricating precise notches or pre-cracks, different cooling rates, casting defects, and compositional fluctuations during vitrification $[16,27]$. The featureless structure of BMGs lacks an obvious length scale to set $\rho_{c}$ and has suggested that the BMGs' notch toughness often decreases with decreasing notch radius $[17,28,29]$. This behavior is concerning for their structural applications since it would suggest that BMGs become increasingly "brittle" with decreasing flaw size. Practically, small flaws are significantly more difficult to avoid than larger flaws during the alloying and vitrification process.

To systematically investigate the effect of notch sharpness on the toughness of BMGs, we introduce a method to fabricate toughness test samples, where we can minimize the previously 
suggested potential sources of error and precisely manipulate the notch radius within $1 \mu \mathrm{m}$ to measure toughness of BMGs in a highly reproducible manner. Our method is based on a combination of thermoplastic forming (TPF) of BMGs in their supercooled liquid region and $\mathrm{Si}$ photolithography. Through this method, we varied the notch radius continuously from precracked to $380 \mu \mathrm{m}$. The effect of the notch radius on the crack fracture behavior was examined for three well studied and representative BMGs, $\mathrm{Zr}_{44} \mathrm{Ti}_{11} \mathrm{Ni}_{10} \mathrm{Cu}_{10} \mathrm{Be}_{25}$ [30], $\mathrm{Pd}_{43} \mathrm{Cu}_{27} \mathrm{Ni}_{10} \mathrm{P}_{20}$ [31], and $\mathrm{Pt}_{57.5} \mathrm{Cu}_{14.7} \mathrm{Ni}_{5.3} \mathrm{P}_{22.5}$ [32]. Surprisingly, and in contrast to expectations and most previous findings $[17,28,29]$, we found that considered BMGs exhibit a specific critical notch radius, $\rho_{c}$. Above $\rho_{c}, K_{Q}$ decreases apparently with decreasing $\rho$ while below $\rho_{c}, K_{Q}$ is independent of $\rho$, suggesting a flaw tolerance behavior. We argue the intrinsic length scale setting $\rho_{c}$ is the BMG's specific shear banding plastic zone size which originates from the BMGs' specific capability in blunting the crack tip.

\section{Experiments}

\subsection{Sample preparation}

In this work, we consider $\mathrm{Zr}_{44} \mathrm{Ti}_{11} \mathrm{Cu}_{10} \mathrm{Ni}_{10} \mathrm{Be}_{25}, \mathrm{Pd}_{43} \mathrm{Cu}_{27} \mathrm{Ni}_{10} \mathrm{P}_{20}$, and $\mathrm{Pt}_{57.5} \mathrm{Cu}_{14.7} \mathrm{Ni}_{5.3} \mathrm{P}_{22.5}$ BMGs. The three alloys represent the wide range of toughness behaviors of BMGs [33]. Master alloy ingots were prepared by arc-melting a mixture of the pure elements in an argon atmosphere with a low oxygen level of $350 \mathrm{ppm}$. The amorphous state was achieved by rapid quenching of alloy melts into a metal mold. The amorphous nature of the BMGs was confirmed by X-ray diffraction (XRD-6000 Shimadzu) and differential scanning calorimeter (Perkin Elmer Diamond DSC).

We employ TPF-based molding to fabricate various single edge notched tension (SENT) samples by replicating BMGs from Si molds. Within our fabrication method, we first design the geometry 
of SENT BMG samples with different notch radii in AutoCAD software. This design is used to construct a photomask with a Heidelberg DWL-66 laser beam writer. Silicon lithography and deep reactive ion etching were subsequently performed to fabricate Si molds with an etching depth of approximately $350 \mu \mathrm{m}$. Replication of the SENT BMG samples was achieved by TPF of BMGs into the $\mathrm{Si}$ molds within $\sim 100$ seconds at $430{ }^{\circ} \mathrm{C}$ under a pressure of $20 \mathrm{MPa}$ for $\mathrm{Zr}_{44} \mathrm{Ti}_{11} \mathrm{Cu}_{10} \mathrm{Ni}_{10} \mathrm{Be}_{25}$, at $365{ }^{\circ} \mathrm{C}$ under a pressure of $5 \mathrm{MPa}$ for $\mathrm{Pd}_{43} \mathrm{Cu}_{27} \mathrm{Ni}_{10} \mathrm{P}_{20}$, or at $270{ }^{\circ} \mathrm{C}$ under a pressure of $1 \mathrm{MPa}$ for $\mathrm{Pt}_{57.5} \mathrm{Cu}_{14.7} \mathrm{Ni}_{5.3} \mathrm{P}_{22.5}$. After molding, the extra $\mathrm{BMG}$ was removed and BMG SENT samples with varying notch radii of pre-cracked, $3 \mu \mathrm{m}, 10 \mu \mathrm{m}, 25 \mu \mathrm{m}, 50 \mu \mathrm{m}$, $100 \mu \mathrm{m}, 150 \mu \mathrm{m}, 230 \mu \mathrm{m}$, and $380 \mu \mathrm{m}$ were released out of Si molds by etching in $20 \%$ (mass fraction) $\mathrm{KOH}$ solution (Fig. 1). The thickness of the BMG SENT samples is approximately 300 $\mu \mathrm{m}$. Overall, we fabricated $\sim 100$ test samples of $\mathrm{Zr}_{44} \mathrm{Ti}_{11} \mathrm{Ni}_{10} \mathrm{Cu}_{10} \mathrm{Be}_{25}, \mathrm{Pd}_{43} \mathrm{Cu}_{27} \mathrm{Ni}_{10} \mathrm{P}_{20}$, and $\mathrm{Pt}_{57.5} \mathrm{Cu}_{14.7} \mathrm{Ni}_{5.3} \mathrm{P}_{22.5}$ with various notch radii (Fig. 1). For the pre-cracked samples, a $2 \mathrm{~Hz}$ cyclic load with a load range of $\Delta K \approx 10 \mathrm{MPa} \sqrt{\mathrm{m}}$, and $K_{\min } / K_{\max } \approx 0.2$ was applied to initiate and grow pre-crack ahead of the $3 \mu \mathrm{m}$ notch using the Instron 5543 tensile machine.

\subsection{Mechanical characterization and analysis}

The notch toughness of all considered SENT samples was evaluated via uniaxial tensile tests which were quasi-static displacement-controlled (strain rate: $10^{-4} \mathrm{~s}^{-1}$ ) on an Instron 5543 tensile testing machine. The precision in fabricating, in particular the notch, is better than $1 \mu \mathrm{m}$ (Fig. 1). This high precision combined with the unique TPF fabrication mitigates most of the extrinsic influences such as casting defects, cooling rate, residual stress, thermal history, and sample fabrication precision. As a consequence, the experimental scatter in $K_{Q}$ measurements using our preparation method is drastically smaller than previously reported [16]. To evaluate reproducibility, $20 \mathrm{Zr}_{44} \mathrm{Ti}_{11} \mathrm{Cu}_{10} \mathrm{Ni}_{10} \mathrm{Be}_{25}$ SENT samples with $\rho=150 \mu \mathrm{m}$ were fabricated and 
tested. For the 20 samples, we measured an average notch toughness of $\overline{K_{Q}}=109 \mathrm{MPa} \sqrt{\mathrm{m}}$ with a standard deviation of only $\sim 3 \mathrm{MPa} \sqrt{\mathrm{m}}$ [34]. Seven samples were prepared and tested for each other notch radius for the considered BMGs to quantify scatter. During deformation, in-situ images were recorded by a home-built Qimaging microscope to capture the plastic zone development in front of the notch (Fig. 2). After fracture, the fractured surface morphology was examined by scanning electron microscopy (SEM). The stress intensity factor $K$ for the SENT geometry is calculated by $K=\sigma \sqrt{\pi a} F\left(\frac{a}{W}\right)$, where $a=4 \mathrm{~mm}$, the notch length, $\sigma$ is the applied far-filed stress, $W=8 \mathrm{~mm}$, the width of the SENT sample, $F\left(\frac{a}{W}\right)=\sqrt{\frac{2 W}{\pi a} \tan \frac{\pi a}{2 W}}$. $\frac{0.752+2.02\left(\frac{a}{W}\right)+0.37\left(1-\sin \frac{\pi a}{2 W}\right)^{3}}{\cos \frac{\pi a}{2 W}}$ is a configuration correction factor [35]. To investigate the validity of the assumption of linear elastic $K$-field dominance, the critical energy release rate $G_{c}$ was also measured and a back-calculated $K_{Q}$ was derived in order to examine the validity of $K$ field approximation in notch toughness characterization of considered BMGs (see Appendix).

\section{Results}

\subsection{Notch radius dependence of $K_{Q}$}

For $\mathrm{Zr}_{44} \mathrm{Ti}_{11} \mathrm{Ni}_{10} \mathrm{Cu}_{10} \mathrm{Be}_{25}$, we found that $K_{Q}$ increases linearly with $\rho^{1 / 2}$ for $\rho>100 \mu \mathrm{m}$. Specifically, $K_{Q}$ increases from $97 \mathrm{MPa} \sqrt{\mathrm{m}}$ for $\rho \leq 100 \mu \mathrm{m}$ up to $143 \mathrm{MPa} \sqrt{\mathrm{m}}$ at $\rho=380 \mu \mathrm{m}$ (Fig. 3a). Below $\rho_{c}, K_{Q} \approx 97 \mathrm{MPa} \sqrt{\mathrm{m}}$ is independent of $\rho$, denoted as $K_{c}$ (Fig. 3a). Hence, this suggests a critical notch radius of $\rho_{c} \approx 100 \mu \mathrm{m}$. For $\mathrm{Pd}_{43} \mathrm{Cu}_{27} \mathrm{Ni}_{10} \mathrm{P}_{20}, K_{Q}$ exhibits a similar qualitative trend but a different $\rho_{c} \approx 30 \mu \mathrm{m}$. Below $\rho_{c}, K_{Q}$ remains approximately constant $\left(K_{Q} \approx\right.$ $46 \mathrm{MPa} \sqrt{\mathrm{m}}$ ) and above $\rho_{c}, K_{Q}$ increases linearly with $\rho^{1 / 2}$ (Fig. 3b). A similar phenomenon of a 
critical notch radius has also been observed in $\mathrm{Pt}_{57.5} \mathrm{Cu}_{14.7} \mathrm{Ni}_{5.3} \mathrm{P}_{22.5}$ (Fig. 3c). Our experimental observation are surprising considering the absence of an intrinsic microstructral length scale and contradicts experimental findings that apparent toughness of BMGs decreases with increasing notch sharpness $[17,28,29]$.

\subsection{Notch radius dependence of plastic zone development}

Mechanistically, plastic deformation of BMGs is achieved through shear banding [36, 37] and the extent of plasticity is a result of competition between shear banding and crack nucleation due to shear induced dilatation or cavitation [5, 24, 38, 39]. Upon loading with an opening stress on the order of the yield strength $\left(\sigma_{y}\right)$, shear localizes into $\sim 15 \mathrm{~nm}$ thick shear bands. Such bands travel along the maximum resolved shear stress orientation. The shear banding process essentially develops a plastic zone. When a shear band propagates to its critical length, it forms a critical shear offset, $\lambda_{c}[40,41]$. This process results in a low bonding strength due to the intervention of cavitation events by the continuous growth of the interior microvoids [38]. As such, shear banding is terminated and final unstable fracture ensues. In order to record the plastic shear banding behavior ahead of the notch tip and correlate the stress-strain curves with the notch propagation, in-situ imaging was carried out by a custom-built optical microscope system during notch toughness testing. This technique enables a quantitative and precise capture of the initial yielding and the plastic zone size that forms by shear banding (Fig. 2). We found that the maximum plastic zone size $\left(R_{p}\right)$ prior to fracture for all considered BMGs exhibits a similar dependence on $\rho$ as observed for $K_{Q}$ versus $\rho$. Namely, for $\rho \leq \rho_{c}, R_{p}$ and $K_{Q}$ are independent of $\rho$ (Fig. 4). Specifically, for $\mathrm{Zr}_{44} \mathrm{Ti}_{11} \mathrm{Cu}_{10} \mathrm{Ni}_{10} \mathrm{Be}_{25}$, a critical plastic zone size of $R_{c p} \approx 350 \pm 16 \mu \mathrm{m}$

corresponding to a critical notch radius of $\rho_{c} \approx 100 \mu \mathrm{m}$ was recorded (Fig. 4a and 4b). For $\mathrm{Pd}_{43} \mathrm{Cu}_{27} \mathrm{Ni}_{10} \mathrm{P}_{20}$ and $\mathrm{Pt}_{57.5} \mathrm{Cu}_{14.7} \mathrm{Ni}_{5.3} \mathrm{P}_{22.5}$ BMGs, $R_{c p} \approx 40 \pm 9 \mu \mathrm{m}, \rho_{c} \approx 30 \mu \mathrm{m}$ (Fig. $4 \mathrm{c}$ and $4 \mathrm{~d}$ ), 
and $R_{c p} \approx 430 \pm 20 \mu \mathrm{m}, \rho_{c} \approx 130 \mu \mathrm{m}$ (Fig. $4 \mathrm{e}$ and $4 \mathrm{f}$ ) were found respectively. With increasing notch radius above the critical radius, $R_{p}$ continuously increases, in accordance with an increase in $K_{Q}$. For instance, $R_{p} \approx 560 \mu \mathrm{m}$ was reached by stable shear banding in $\mathrm{Zr}_{44} \mathrm{Ti}_{11} \mathrm{Cu}_{10} \mathrm{Ni}_{10} \mathrm{Be}_{25}$ for $\rho=380 \mu \mathrm{m}$.

\subsection{Notch radius dependence of critical shear offset}

We found that the scaling of the plastic zone with $\rho$ above $\rho_{c}$ results in a higher critical shear offset, $\lambda_{c}$, by extended shear banding activities as observed on the fractured surface. Variation of $\rho$ below $\rho_{c}$ leaves $\lambda_{c}$ essentially unchanged (Fig. 5). For instance, for $\mathrm{Zr}_{44} \mathrm{Ti}_{11} \mathrm{Ni}_{10} \mathrm{Cu}_{10} \mathrm{Be}_{25}$, we found that $\lambda_{c}$ scales directly with $\rho$ for $\rho \geq \rho_{c} \approx 100 \mu \mathrm{m}$. Specifically, $\lambda_{c}$ increases from $\sim 13 \mu \mathrm{m}$ for $\rho \leq 100 \mu \mathrm{m}$ up to $21 \mu \mathrm{m}$ at $\rho=380 \mu \mathrm{m}$, and $\lambda_{c}$ of $\mathrm{Pd}_{43} \mathrm{Cu}_{27} \mathrm{Ni}_{10} \mathrm{P}_{20}$ and $\mathrm{Pt}_{57.5} \mathrm{Cu}_{14.7} \mathrm{Ni}_{5.3} \mathrm{P}_{22.5}$ BMGs demonstrates a qualitatively similar behavior (Fig. 5).

\section{Discussion}

\subsection{Theoretical description of $\rho_{c}$}

The primary effect of a notch including a crack is bringing a stress intensification field and a stress singularity ahead of the notch tip subjected to loading. When a BMG SENT sample is continuously loaded, it elastically deforms until the local longitudinal tensile stress, $\sigma_{y y}$, developed at the notch root reaches the yield stress, $\sigma_{y}$, after which a plastic zone forms and spread into the ligament in front of the notch tip. The formation of a plastic zone redistributes the stress field ahead of the notch tip. The stress distribution within the plastic zone depends on material's constitutive law, yielding criterion, and geometry. The plastic zone size is generally

expressed as $R_{p} \approx c\left(K_{Q} / \sigma_{y}\right)^{2}$, where $c$ is a constant related to test sample's geometry and Poisson ratio. For example, $\mathrm{c} \approx 0.12$ for plane strain condition $[7,18]$. Based on the notch blunting stress 
field theory [42], the apparent notch toughness, $K_{Q}$, scales directly with $\rho^{1 / 2}$. Our results can be well described with this scaling for $\rho>\rho_{c}$ (Fig. 2). Based on this scaling, $K_{Q}$ and hence the plastic zone (for a specific BMG) would continuously decrease and approach zero when increasing the notch acuity to infinitely sharp (i.e., $\rho \approx 0$ for a pre-crack). Such ideally brittle behavior does not occur in our experiments. In fact, in crystalline materials, Tetelman [8, 43], Irwin [44], and Cottrell [45] et al. extended this scaling law and proposed a concept of critical notch radius $\left(\rho_{c}\right)$ below which $\rho$ is set by $\rho=\rho_{c}$, and thereby $K_{Q}$ and $R_{p}$ are invariant for $\rho \leq \rho_{c}$, denoted as $K_{c}$ and $R_{c p}$, respectively. They have attributed the mechanistic origin of $\rho_{c}$ to the characteristic microstructural features in crystalline materials such as grain size and secondary phase spacing that inherently dominate the fracture path and fracture toughness. Interestingly, we found that the dependence of notch toughness and plastic zone size on notch radius in BMGs follows a similar trend. Our experimental results (Fig. 3) reveal $K_{c} \approx 97 \mathrm{MPa} \sqrt{\mathrm{m}}$ for $\mathrm{Zr}_{44} \mathrm{Ti}_{11} \mathrm{Cu}_{10} \mathrm{Ni}_{10} \mathrm{Be}_{25}$, which yields at $\sigma_{y} \approx 1900 \mathrm{MPa}$ [46]. Hence, a critical plastic zone size $R_{c p}$ $\approx 313 \mu \mathrm{m}$ is calculated provided plane strain condition $\left(R_{p} \approx 0.12\left(K_{Q} / \sigma_{y}\right)^{2}\right)[7,18]$, which is comparable to the observed critical plastic zone size of $R_{c p} \approx 350 \pm 16 \mu \mathrm{m}$ when $\rho \leq \rho_{c} \approx 100 \mu \mathrm{m}$ (Fig. 4). Similarly, the calculated plane strain $R_{c p} \approx 440 \mu \mathrm{m}$ is very close to the experimentally measured $R_{c p} \approx 430 \pm 20 \mu \mathrm{m}$ for $\mathrm{Pt}_{57.5} \mathrm{Cu}_{14.7} \mathrm{Ni}_{5.3} \mathrm{P}_{22.5}$ where $K_{c} \approx 85 \mathrm{MPa} \sqrt{\mathrm{m}}$ and $\sigma_{y} \approx 1400 \mathrm{MPa}$ [32]. Considering the small thickness $(\sim 300 \mu \mathrm{m})$ of the specimens we considered here, the result that the measured $R_{c p}$ is comparable to the theoretically estimated plane strain plastic zone is surprising. In fact, measuring the intrinsic plane strain fracture toughness has been prohibitively challenging for the majority of BMGs, particularly for tough ones, due to the geometrical limitations set by the critical casting thickness [5, 32, 47-50]. According to the recommendation of ASTM E399, for the determination of the intrinsic plane-strain toughness, $K_{I c}$, the specimen 
thickness $t$, the notch length $a$, and the length of the uncracked ligament $(W-a)$ all need to exceed $2.5\left(\frac{K_{c}}{\sigma_{y}}\right)^{2}$, or at least the uncracked ligament length and the thickness should exceed 10 times the plastic zone size. Therefore, for example, for $\mathrm{Zr}_{44} \mathrm{Ti}_{11} \mathrm{Cu}_{10} \mathrm{Ni}_{10} \mathrm{Be}_{25}$ with $\rho=380 \mu \mathrm{m}$, geometric requirements are: $a, t, W-a \geq 14 \mathrm{~mm}$ based on the above equation. This geometry is difficult to achieve even considering the high glass forming ability, which is reflected in a critical casting dimension of $\sim 10 \mathrm{~mm}$ [51]. Furthermore, it is unclear if this standard which has been developed primarily for crystalline materials are applicable to BMGs. For example, the mechanical work in the plastic zone of crystalline metals is typically accomplished through uniformly (on the length scale of the plastic zone) distributed dislocation movements. In contrast, the plastic zone of BMGs is dissipated into highly localized narrow shear bands. Hence, for tough BMGs, $K_{Q}$ instead of $K_{I c}$ is often determined. To systematically investigate the effect of sample thickness, SENT samples with different thicknesses of $50 \mu \mathrm{m}, 200 \mu \mathrm{m}, 300 \mu \mathrm{m}, 1.04 \mathrm{~mm}, 1.2 \mathrm{~mm}, 2 \mathrm{~mm}$, $3.1 \mathrm{~mm}, 4 \mathrm{~mm}, 4.5 \mathrm{~mm}$ for $\mathrm{Zr}_{44} \mathrm{Ti}_{11} \mathrm{Cu}_{10} \mathrm{Ni}_{10} \mathrm{Be}_{25}$ were prepared by TPF of MGs into a different metal mold and subsequent notch introduction $(\rho \approx 150 \mu \mathrm{m})$ through electro-discharge machining. We measured $K_{Q}$ values within the range of $92 \sim 123 \mathrm{MPa} \sqrt{\mathrm{m}}(\sim 20 \%$ relative difference) over considered wide thickness range. Determined $K_{Q}$ values are also comparable to the reported notch toughness of $K_{Q} \approx 105 \mathrm{MPa} \sqrt{\mathrm{m}}$ (with a similar notch radius) for a similar Zrbased BMG, $\mathrm{Zr}_{41.2} \mathrm{Ti}_{13.8} \mathrm{Cu}_{12.5} \mathrm{Ni}_{10.0} \mathrm{Be}_{22.5}$, with sample thicknesses of $4 \mathrm{~mm}$ and $7 \mathrm{~mm}$ [17]. The small variation in $K_{Q}$ of $\sim 20 \%$ over considered wide thickness range $50 \mu \mathrm{m}$ to $7 \mathrm{~mm}$ suggests that BMGs' thickness affects the notch toughness significantly less than typically observed for conventional crystalline metals [52]. Observed small thickness variation also promotes our sample preparation method which is limited to $\sim 500$ micron thick samples, but with the advantages of highest relative accuracy in flaw tolerance measurements. The range of considered 
alloys suggests that a flaw tolerance behavior generally exists in BMGs. An open question that we cannot unambiguously answer and deserves further investigation is whether or not the small observed thickness effect has an effect on the absolute value of $\rho_{c}$. From a practical viewpoint, most of current and envisioned BMG applications such as electronic casings, biomedical implants, sensors, and watch micro-parts require thin BMGs below $\sim 1 \mathrm{~mm}$. In this regard, the flaw tolerance revealed in our study for thin BMG samples are particularly encouraging and directly applicable for BMGs' applications.

In general, the fracture criterion of a material, which connects the fracture mechanics to an underlying mechanism, is either stress- or strain-based [53, 54]. It is hitherto unclear if BMGs obey a critical stress or a critical strain controlled fracture criterion [16]. Both criteria have been employed to illustrate the fracture mechanism of BMGs. For example, Tandaiya et al. [55] suggested that the fracture process of ductile BMGs is mechanistically dominated by a critical strain in a dominant shear band. Such critical strain controlled fracture criterion can be readily applied for simulation-based toughness predictions since it corresponds to a continuum description and has been successfully linked to a critical process zone size (stable crack growth length ahead of the crack tip), especially under mix-mode loading [55]. On the other hand, the observation that fracture of BMGs is very sensitive to normal pressure, and thereby a critical normal stress controlled fracture criterion has also been proposed to illustrate the fracture of BMGs $[28,56]$. A critical material length scale is usually required towards establishing a fracture criterion. Here, we experimentally observe a specific $\rho_{c}$ and the fracture behaviors revealed here for the considered BMGs may provide insight into understanding BMGs' intrinsic material length scale, which is a key aspect in understanding the wide range of fracture toughness and the fracture criterion within the material class of BMGs. 


\subsection{Mechanistic origin of $\rho_{c}$ and a critical characteristic distance}

A critical notch radius behavior has been widely studied and reported for different material classes including crystalline metals, ceramics, and glassy polymers [7-11, 57]. The success of the notch blunting stress field theory in interpreting the critical notch radius effect in numerous material classes raises the question about the mechanistic origin or physical meaning of the critical notch radius, $\rho_{c}$, and its associated critical plastic zone size, $R_{c p}$. In general, the flaw tolerance can be essentially understood by a material's intrinsic characteristic distance $\left(d_{c}\right)$ or the minimum critical distance over which the critical fracture stress or strain is reached to cause fracture. In crystalline materials, the parameter $d_{c}$ is often related to microstructural features such as grain size, spacing of inclusions, spacing of second phases, or twin band spacing [7, 43, 54, 58]. The key role of these microstructural features in controlling the mechanical behavior and the fracture of the material has been understood by micro-mechanistic models such as the RitchieKnott-Rice model [54]. In contrast, in amorphous polymers, the physical meaning for this critical characteristic distance is less clear $[59,60]$. Some work proposed that this characteristic distance in glassy polymers may correspond to the size at which the critical crazing plastic damage zone forms before cracking [59-61]. The crazing mechanism is based on a dilatational process which is operated by accumulation of microscopic voids to form micro-crack [60, 62].

The precision and repeatability of the introduced method has allowed us to clearly and precisely identify the flaw tolerance (critical flaw size) behavior in specific but representative BMGs. Such flaw tolerance behavior is surprising for BMGs considering their featureless microstructure. Mechanistic origins such as microstructural features in crystalline metals or crazing in amorphous polymers cannot be applied to BMGs. In amorphous metals with their featureless microstructure, a similar mechanism than in crystalline metals should not exist and it is 
inconclusive about the response of flaws (size) to the apparent toughness of BMGs. Through our precise approach, we have experimentally revealed that the specific ability of a BMG to blunt a crack to a specific level mechanistically gives rise to a critical flaw size that the BMG can tolerate and the shear banding process forms a critical plastic zone size. Our experimental observations suggest that the characteristic distance $\left(d_{c}\right)$ in BMGs is set by the critical shear offset, $\lambda_{c}$, which is associated with the BMGs' inherent capability of blunting a crack tip to a maximum radius. Quantitatively, $\lambda_{c}$ has been correlated with the apparent notch crack growth by blunting through careful fracture morphology measurements, and an approximate relation of $\lambda_{c} \approx$ $0.5^{*} C T O D$ (crack tip opening displacement) has been experimentally measured [55]. Based on fracture mechanics, CTOD $\approx \frac{K c^{2}}{E \sigma_{y}}[52]$. Therefore, $\lambda_{c} \approx \frac{K c^{2}}{2 E \sigma_{y}}$, which is comparable to our experimental findings for considered BMGs. More interestingly, we found $\rho_{c} \approx 3 \sim 4 * C T O D$ for all considered BMGs. This is surprisingly similar to the characteristic fracture length scale of "fracture process zone size", which was measured approximately $3 \sim 4 * C T O D$ as well for $\mathrm{Zr}_{41.2} \mathrm{Ti}_{13.8} \mathrm{Cu}_{12.5} \mathrm{Ni}_{10.0} \mathrm{Be}_{22.5} \mathrm{BMG}$ by Tandaiya et al. [52]. Based on the BMGs' specific blunting capabilities, we propose a schematic mechanism for the observed notch radius dependence of $K_{Q}$, fracture process zone size, and the plastic zone size for BMGs (Fig. 6). As the far field stress $\sigma$ increases, the local stress at the notch tip reaches the yield stress and plastic deformation occurs through highly localized shear bands $[36,37,63,64]$. Further loading to a higher stress is accompanied by crack growth and propagation of shear bands to form a distinguishable plastic zone size. Strain energy is released through shear offset over the free surfaces (e.g., cracked surfaces) $[40,56]$. Such accumulated shear offsets from multiple shear bands on the cracked surfaces result in displacement component along the loading direction and as a consequence, the crack tip blunts, as similarly observed in previous reports $[21,22,55,65]$. This scenario proceeds 
until the crack tip cannot blunt further and the fracture process zone size is reached at the plasticelastic interface. Therefore, shear banding is terminated and fracture occurs when the shear offset approaches a critical value, $\lambda_{c}$. In this respect, $\lambda_{c}$ on the cracked surfaces (Fig. 5) sets the plastic zone size and the BMGs' inherent capability of crack blunting. This evolution depends on the initial notch radius (Fig. 6b). For sharp notches with $\rho<\rho_{c}$, the stress concentrations ahead of the notches are higher. The inherent crack blunting capability allows reducing the stress concentration and blunting the notch tip to a certain level and the fracture process zone size grows until a critical value of $F_{c p}$ is attained when fracture occurs at a plastic zone distance of $R_{c p}$. This is essentially similar to the case for $\rho=\rho_{c}$. Such an intrinsic characteristic distance of $R_{c p}$ determines minimum allowable plastic deformation activities and the critical bound where fracture occurs and hence dictates the inherent fracture toughness of BMGs. For notches with $\rho>$ $\rho_{c}$, the stress concentration intensity is lower. In this case, the plastic deformation is postponed to an increased distance larger than $R_{c p}$, which reflects in the observed continually increased plastic zone size with increasing $\rho$ (Fig. 4). Such increased plastic zone is associated with a higher shear offset as observed on the fractured surface (Fig. 5), and a higher critical fracture process zone size. As a consequence, the two distinct behaviors suggest that the apparent toughness of BMGs decreases with decreasing the flaw sizes until a critical value of $\rho_{c}$, below which apparent toughness and flaws are "indistinguishable" from $\rho_{c}$.

\subsection{Implications of $\rho_{c}$ and $\boldsymbol{R}_{c p}$ : flaw tolerance of BMGs}

The critical notch radius with corresponding critical distance $R_{c p}$ sets the minimum allowed plastic zone size even when the notch is infinitely sharp. This implies that BMGs containing sharp cracks or micro-cracks with $\rho<\rho_{c}$ are as tough as those containing flaws with $\rho_{c}$. Hence, the existence of $\rho_{c}$ prevents the degradation of toughness to become negligibly small for BMGs 
that contain sharp flaws. This is practically encouraging for BMGs' structural applications since flaws smaller than $\rho_{c}$ are increasingly more difficult to avoid but are "indistinguishable" in their influence to the fracture toughness.

Observed flaw tolerance has also ramifications for test sample requirements. In general, fatigue pre-cracking is required to evaluate the toughness of a material. However, fatigue pre-cracking may cause sample damage, residual stresses, and results in a poorly controllable crack direction [59]. Often fatigue pre-cracking of a material is not feasible such as in brittle or quasi-brittle materials like casting steels, ceramics, and brittle BMGs where the required range of fatigue stress levels are too narrow [59]. A convenient benefit of the observed flaw resistance is that the intrinsic pre-crack toughness of BMGs can be predicted from notch toughness tests, which we have shown for the three considered BMGs.

\section{Conclusions}

In summary, we revealed that for BMGs a critical notch radius, $\rho_{c}$, exists, above which notch toughness decreases apparently with decreasing $\rho$, while below $\rho_{c}$ notch toughness is independent of $\rho$. This behavior suggests a tolerance to flaws that are smaller than $\rho_{c}$. Similar to materials with an intrinsic microstructural length scale, the fracture of BMGs can be described by a critical material length scale. We argue that the critical notch radius is set by the intrinsic critical shear banding plastic zone size $\left(R_{c p}\right)$ associated with the inherent crack blunting ability in BMGs. The intrinsic plastic zone and the flaw tolerance found in BMGs are encouraging for structural applications. More generally, the existence of a critical flaw size may provide novel insights into understanding the physical origins of the critical distance phenomena governing fracture of a notch in seemingly featureless materials. 


\section{Acknowledgments}

This work was supported by the Department of Energy through the Office of Basic Energy Sciences (\#DE SC0004889). Experimental assistance from Michael Kanik is gratefully acknowledged.

\section{References:}

[1] B.R. Lawn, Fracture of brittle solids, Cambridge University Press, 1993.

[2] J.C. Williams, Jr. E.A. Starke, Progress in structural materials for aerospace systems. Acta Mater. 51 (2003) 5775-5799.

[3] A. Fitzgerald, R.H. Dauskardt, T. Kenny, Fracture toughness and crack growth phenomena of plasma-etched single crystal silicon. Sensor Actuat. A-Phys. 83 (2000) 194-199.

[4] E.A. Zimmermann, E. Schaible, H. Bale, H.D. Barth, S.Y. Tang, P. Reichert, B. Busse, T. Alliston, J.W. Ager III, R.O. Ritchie, Age-related changes in the plasticity and toughness of human cortical bone at multiple length scales. Proc. Natl. Acad. Sci. USA 108 (2011) 1441614421.

[5] M.D. Demetriou, G. Garrett, J.P. Schramm, D.C. Hofmann, W.L. Johnson, R.O. Ritchie, A damage-tolerant glass. Nat. Mater. 10 (2011) 123-128.

[6] A. García-Prieto, C. Baudín, Influence of experimental variables on fracture toughness determined on SEVNB in three points bending. Mullite a case study. J. Eur. Ceram. Soc. 32 (2012) 4241-4248.

[7] R.O. Ritchie, B. Francis, W.L. Server, Evaluation of toughness in AISI 4340 alloy steel austenitized at low and high temperatures. Metall. Trans. A 7 (1976) 831-838.

[8] T. Wilshaw, C. Rau, A. Tetelman, A general model to predict the elastic-plastic stress 
distribution and fracture strength of notched bars in plane strain bending. Eng. Fract. Mech. 1 (1968) 191-211.

[9] R. Damani, R. Gstrein, R. Danzer, Critical notch-root radius effect in SENB-S fracture toughness testing. J. Eur. Ceram. Soc. 16 (1996) 695-702.

[10] S. Kamat, J. Hirth, F. Zok, Effects of notch root radius on crack initiation and growth toughnesses of a cross-ply Ti6Al4V/SiC composite. Acta Mater. 44 (1996) 1831-1838.

[11] K.C. Shekar, M.N. Kumar, P.K. Subramanian, A. Kumar, B.A. Prasad, N.E. Prasad, Effect of Notch Root Radius on the Apparent Fracture Toughness in CNT and Carbon Fiber Reinforced, Epoxy-Matrix Hybrid Composite. Trans. Indian Inst. Met. 67 (2014) 33-39.

[12] W.L. Johnson, Bulk glass-forming metallic alloys: Science and technology. MRS Bull. 24 (1999) 42-56.

[13] C.A. Schuh, T.C. Hufnagel, U. Ramamurty, Mechanical behavior of amorphous alloys. Acta Mater. 55 (2007) 4067-4109.

[14] W.H. Wang, C. Dong, C.H. Shek, Bulk metallic glasses. Mater. Sci. Eng. R 44 (2004) 45-89. [15] X.K. Xi, D. Q. Zhao, M. X. Pan, W. H. Wang, Y. Wu, J. J. Lewandowski, Fracture of Brittle Metallic Glasses: Brittleness or Plasticity. Phys. Rev. Lett. 94 (2005) 125510.

[16] J. Xu, U. Ramamurty, E. Ma, The fracture toughness of bulk metallic glasses. JOM 62 (2010) 10-18.

[17] P. Lowhaphandu, J.J. Lewandowski, Fracture toughness and notched toughness of bulk amorphous alloy: Zr-Ti-Ni-Cu-Be. Scr. Mater. 38 (1998) 1811-1817.

[18] R.D. Conner, A.J. Rosakis, W.L. Johnson, D.M. Owen, Fracture toughness determination for a beryllium-bearing bulk metallic glass. Scr. Mater. 37 (1997) 1373-1378.

[19] C.J. Gilbert, V. Schroeder, R.O. Ritchie, Metall. Mater. Trans. A 30 (1999) 1739-1753. 
[20] D. Suh, R.H. Dauskardt, J. Non-cryst. Solids 317 (2003) 181-186.

[21] K.M. Flores, R.H. Dauskardt, Enhanced toughness due to stable crack tip damage zones in bulk metallic glass. Scr. Mater. 41 (1999) 937-943.

[22] K.M. Flores, R.H. Dauskardt, Crack-tip plasticity in bulk metallic glasses. Mater. Sci. Eng. A319-321 (2001) 511-515.

[23] K.M. Flores, R.H. Dauskardt, Mode II fracture behavior of a Zr-based bulk metallic glass. J. Mech. Phys. Solids 54 (2006) 2418-2435.

[24] P. Tandaiya, U. Ramamurty, R. Narasimhan, Mixed mode (I and II) crack tip fields in bulk metallic glasses. J. Mech. Phys. Solids 57 (2009) 1880-1897.

[25] R.L. Narayan, T. Tandaiya, G.R. Garrett, M.D. Demetriou, U. Ramamurty, On the variability in fracture toughness of "ductile" bulk metallic glasses. Scr. Mater. 102 (2015) 75-78.

[26] B. Gludovatz, S.E. Naleway, R.O. Ritchie, J.J. Kruzic, Size-dependent fracture toughness of bulk metallic glasses. Acta Mater. 70 (2014) 198-207.

[27] B.A. Sun, W.H. Wang, The fracture of bulk metallic glasses. Prog. Mater. Sci. 74 (2015) 211-307.

[28] J.J. Lewandowski, M. Shazly, A. Shamimi Nouri, Intrinsic and extrinsic toughening of metallic glasses. Scr. Mater. 54 (2006) 337-341.

[29] K. Fujita, A. Okamoto, N. Nishiyama, Y. Yokoyama, H. Kimura, A. Inoue, Effects of loading rates, notch root radius and specimen thickness on fracture toughness in bulk metallic glasses. J. Alloys Compd. 434-435 (2007) 22-27.

[30] W. Chen, Z. Liu, J. Schroers, Joining of bulk metallic glasses in air. Acta Mater. 62 (2014) 49-57.

[31] C. Ma, A. Inoue, Deformation and fracture behaviors of Pd-Cu-Ni-P glassy alloys. Mater. 
Trans. 43 (2002) 3266-3272.

[32] J. Schroers, W.L. Johnson, Ductile Bulk Metallic Glass, Phys. Rev. Lett. 93 (2004) 255506.

[33] G. Kumar, P. Neibecker, Y.H. Liu, J. Schroers, Critical Fictive Temperature for ductility in metallic glasses. Nat. Comm. 4 (2013) 1536.

[34] W. Chen, J. Ketkaew, Z. Liu, R. Mota, K. O'Brien, C.S. da Siva, J. Schroers, Does the fracture toughness of bulk metallic glasses scatter? Scr. Mater. 107 (2015) 1-4.

[35] H. Tada, P. Paris, G. Irwin, The Analysis of Cracks Handbook, New York ASME Press, 2000.

[36] F. Spaepen, A microscopic mechanism for steady state inhomogeneous flow in metallic glasses. Acta Metall. 25 (1977) 407-415.

[37] A. Argon, Plastic deformation in metallic glasses. Acta Metall. 27 (1979) 47-58.

[38] E. Bouchaud, D. Boivin, J.-L. Pouchou, D. Bonamy, B. Poon, G. Ravichandran, Fracture through cavitation in a metallic glass. Europhys. Lett. 83 (2008) 66006.

[39] P. Murali, T. F. Guo, Y.W. Zhang, R. Narasimhan, Y. Li, H. J. Gao, Atomic Scale Fluctuations Govern Brittle Fracture and Cavitation Behavior in Metallic Glasses. Phys. Rev. Lett. 107 (2011) 215501.

[40] R.D. Conner, W.L. Johnson, N.E. Paton, W.D. Nix, Shear bands and cracking of metallic glass plates in bending. J. Appl. Phys. 94 (2003) 904-911.

[41] R.D. Conner, Y. Li, W.D. Nix, W.L. Johnson, Shear band spacing under bending of Zrbased metallic glass plates. Acta Mater. 52 (2004) 2429-2434.

[42] J.R. Rice, M.A. Johnson, Inelastic Behavior of Solids. New York, McGraw-Hill, 1970. p. 641-672.

[43] A. Tetelman, T. Wilshaw, Jr. C. Rau, The critical tensile stress criterion for cleavage. Int. J. 
Fract. Mech. 4 (1968) 147-156.

[44] G. Irwin, Structural aspects of brittle fracture. Appl. Mater. Res. 3 (1964) 65-81.

[45] A.H. Cottrell, Mechanics of fracture in large structures. Proc. R. Soc. A 285 (1965) 10-21.

[46] H.A. Bruck, T. Christman, A.J. Rosakis, W.L. Johnson, Quasi-static constitutive behavior of $\mathrm{Zr}_{41.25} \mathrm{Ti}_{13.75} \mathrm{Ni}_{10} \mathrm{Cu}_{12.5} \mathrm{Be}_{22.5}$ bulk amorphous alloys. Scr. Mater. 30 (1994) 429-434.

[47] M.D. Demetriou, G. Kaltenboeck, J.-Y. Suh, G. Garrett, M. Floyd, C. Crewdson, D.C. Hofmann, H. Kozachkov, A. Wiest, J.P. Schramm, W.L. Johnson, Glassy steel optimized for glass-forming ability and toughness. Appl. Phys. Lett. 95 (2009) 041907.

[48] Z.D. Zhu, P. Jia, J. Xu, Optimization for toughness in metalloid-free Ni-based bulk metallic glasses. Scr. Mater. 64 (2011) 785-788.

[49] P. Jia, Z.D. Zhu, E. Ma, J. Xu, Notch toughness of Cu-based bulk metallic glasses. Scr. Mater. 61 (2009) 137-140.

[50] S.F. Guo, J.L. Qiu, S.H. Xie, W. Chen, Fe-based bulk metallic glasses: Brittle or ductile? Appl. Phys. Lett. 105 (2015) 161901.

[51] A. Peker, W.L. Johnson, A highly processable metallic glass: $\mathrm{Zr}_{41.2} \mathrm{Ti}_{13.8} \mathrm{Cu}_{12.5} \mathrm{Ni}_{10.0} \mathrm{Be}_{22.5}$. Appl. Phys. Lett. 63 (1993) 2342.

[52] T.L. Anderson, Fracture mechanics: fundamentals and applications, CRC Press, 2005.

[53] F. McClintock, G. Irwin, Plasticity aspects of fracture mechanics: Fracture toughness testing and its applications, ASTM STP (2 ${ }^{\text {nd }}$ Ed.) 381 (1965) 84-113.

[54] R.O. Ritchie, J.F. Knott, J.R. Rice, On the relationship between critical tensile stress and fracture toughness in mild steel. J. Mech. Phys. Solids 21 (1973) 395-510.

[55] P. Tandaiya, R. Narasimhan, U. Ramamurty, On the mechanism and the length scales involved in the ductile fracture of a bulk metallic glass, Acta Mater. 61 (2013) 1558-1570. 
[56] Z.F. Zhang, J. Eckert, L. Schultz, Difference in compressive and tensile fracture mechanisms of $\mathrm{Zr}_{59} \mathrm{Cu}_{20} \mathrm{Al}_{10} \mathrm{Ni}_{8} \mathrm{Ti}_{3}$ bulk metallic glass. Acta Mater. 51 (2003) 1167-1179.

[57] S. Cicero, V. Madrazo, I. Carrascal, Analysis of notch effect in PMMA using the Theory of Critical Distances. Eng. Fract. Mech. 86 (2012) 56-72.

[58] A.H. Cottrell, The mechanical properties of materials, John Wiley, 1964.

[59] D. Taylor, The theory of critical distances: a new perspective in fracture mechanics, Elsevier, 2010.

[60] H.E. Meijer, L.E. Govaert, Mechanical performance of polymer systems: the relation between structure and properties. Prog. Polymer. Sci. 30 (2005) 915-938.

[61] I. Constable, L. Culver, J. Williams, Notch root radii effects in the fatigue of polymers. Int. J. Fract. Mech. 6 (1970) 279-285.

[62] R. Kambour, A review of crazing and fracture in thermoplastics. J. Polymer. Sci. Macromolecular Rev. 7 (1973) 1-154.

[63] A.L. Greer, Y.Q. Cheng, E. Ma, Shear bands in metallic glasses. Mater. Sci. Eng. R 74 (2013) 71-132.

[64] Y. Zhang, A. L. Greer, Thickness of shear bands in metallic glasses. Appl. Phys. Lett. 89 (2006) 071907.

[65] C.J. Gilbert, R.O. Ritchie, W.L. Johnson, Fracture toughness and fatigue-crack propagation in a $\mathrm{Zr}-\mathrm{Ti}-\mathrm{Ni}-\mathrm{Cu}-\mathrm{Be}$ bulk metallic glass. Appl. Phys. Lett. 71 (1997) 476-478. 


\section{Appendix}

\section{Critical energy release rate $\left(G_{c}\right)$ measurement}

To examine the validity of the assumption of small scale yielding based $K$-field dominance, the energy release rate $G_{c}=-\lim _{\Delta a \rightarrow 0} \frac{\Pi(a+\Delta a)-\Pi(a-\Delta a)}{2 \Delta a}$ is further measured, where $\Pi(a+\Delta a)-$ $\Pi(\mathrm{a}-\Delta \mathrm{a})$ are the potential energy difference during a notch crack propagation of $2 \Delta a$ distance. The unique TPF-based fabrication allows us to precisely control the notch length $( \pm 1 \mu \mathrm{m})$. Since $\mathrm{Zr}_{44} \mathrm{Ti}_{11} \mathrm{Cu}_{10} \mathrm{Ni}_{10} \mathrm{Be}_{25}$ is relatively the toughnest in the three considered BMGs, we fabricated $\mathrm{Zr}_{44} \mathrm{Ti}_{11} \mathrm{Cu}_{10} \mathrm{Ni}_{10} \mathrm{Be}_{25} \mathrm{SENT}$ specimens $(\rho=150 \mu \mathrm{m})$ with notch lengths of $a \pm \Delta a$, where $\Delta a=5 \%$ $a$ (i.e., $\Delta a=0.2 \mathrm{~mm}$ ). The fracture stresses of the specimens with different notch lengths of $a=$ $3.8,4.0$, and $4.2 \mathrm{~mm}$, were measured as $\sigma_{1}=367 \mathrm{MPa}, \sigma_{2}=338 \mathrm{MPa}, \sigma_{3}=310 \mathrm{MPa}$, respectively. Therefore, $G_{c}$ can be measured by the differential fracture stress for different notch length specimens

$$
\frac{1}{2} \frac{\sigma_{1}^{2}-\sigma_{3}^{2}}{\mathrm{E}^{\prime}} \cdot \mathrm{t} \cdot \mathrm{W} \cdot \mathrm{L}=2 \Delta \mathrm{a} \cdot \mathrm{G}_{\mathrm{C}} \cdot \mathrm{t}
$$

where $E^{\prime} \approx 100 \mathrm{GPa}$ is Young's modulus $[30,46]$; $t$ sample thickess, $L=35.5 \mathrm{~mm}$ sample gauge length (spacing of two loading pins between two ends); $W=8 \mathrm{~mm}$ sample width. Consequently, $G_{c} \approx 0.137 \mathrm{MPa} \cdot \mathrm{m}$ was measured. A back-calculated $K_{Q}=\sqrt{G_{c} E^{\prime}} \approx 117 \mathrm{MPa} \sqrt{\mathrm{m}}$ for $\rho=150$ $\mu \mathrm{m}$ is similar to the measured value of $109 \mathrm{MPa} \sqrt{\mathrm{m}}$ by the $K$-field method, suggesting the validity of the small scale yielding based $K$-field approximation in notch toughness characterization of considered BMGs. 


\section{Figure Captions}

Figure 1 Schematic illustration of the fabrication method of BMG SENT samples. (A) Using Si lithography and deep reactive ion etching, Si molds are fabricated $(a-d)$. Thermoplastic molding is employed to replicate the mold into the BMG (e - g). An enlarged SEM view of $\rho=3 \mu \mathrm{m}$ suggests a notch tip fabrication precision of $\sim 1 \mu \mathrm{m}$ by this approach. (B) Pre-crack $(\rho \approx 0 \mu \mathrm{m})$ and notches with different radii are fabricated into SENT sample. Pre-crack image was taken under an applied stress to enhance the visualization. (C) 100 BMG SENT samples that we consider for notch toughness testing with different notch radii for $\mathrm{Zr}_{44} \mathrm{Ti}_{11} \mathrm{Cu}_{10} \mathrm{Ni}_{10} \mathrm{Be}_{25}$, $\mathrm{Pd}_{43} \mathrm{Cu}_{27} \mathrm{Ni}_{10} \mathrm{P}_{20}$, and $\mathrm{Pt}_{57.5} \mathrm{Cu}_{14.7} \mathrm{Ni}_{5.3} \mathrm{P}_{22.5}$ BMGs.

Figure 2 A representative load - displacement curve and the corresponding plastic zone development are recorded during loading through the home-built in-situ optical microscope. This technique allows for capturing the plastic zone size of $R_{p}$ at fracture. Example is for $\mathrm{Zr}_{44} \mathrm{Ti}_{11} \mathrm{Cu}_{10} \mathrm{Ni}_{10} \mathrm{Be}_{25}, \rho=150 \mu \mathrm{m}$.

Figure 3 Notch radius dependence of $K_{Q}$ of considered BMGs. A specific $\rho_{c} \approx 100 \mu \mathrm{m}(\mathrm{A}), \rho_{c} \approx$ $30 \mu \mathrm{m}(\mathrm{B})$, and $\rho_{c} \approx 130 \mu \mathrm{m}(\mathrm{C})$ are found for $\mathrm{Zr}_{44} \mathrm{Ti}_{11} \mathrm{Cu}_{10} \mathrm{Ni}_{10} \mathrm{Be}_{25}, \mathrm{Pd}_{43} \mathrm{Cu}_{27} \mathrm{Ni}_{10} \mathrm{P}_{20}$, and $\mathrm{Pt}_{57.5} \mathrm{Cu}_{14.7} \mathrm{Ni}_{5.3} \mathrm{P}_{22.5}$, respectively. Above $\rho_{c}, K_{Q}$ scales linearly with $\rho^{1 / 2}$. Seven test specimens were prepared and tested for each considered notch radius to quantify error.

Figure 4 Effect of notch radius on the plastic zone size prior to fracture. (A), (C), and (E) In-situ captured $R_{p}$ ahead of different notch radii of $\mathrm{Zr}_{44} \mathrm{Ti}_{11} \mathrm{Cu}_{10} \mathrm{Ni}_{10} \mathrm{Be}_{25}, \mathrm{Pd}_{43} \mathrm{Cu}_{27} \mathrm{Ni}_{10} \mathrm{P}_{20}$, and $\mathrm{Pt}_{57.5} \mathrm{Cu}_{14.7} \mathrm{Ni}_{5.3} \mathrm{P}_{22.5}$, respectively. Scale bar: $300 \mu \mathrm{m}$. (B), (D), and (F) As $\rho \leq \rho_{c}, R_{p}$ is approximately constant, denoted as $R_{c p} \approx 350 \pm 16 \mu \mathrm{m}$ for $\mathrm{Zr}_{44} \mathrm{Ti}_{11} \mathrm{Cu}_{10} \mathrm{Ni}_{10} \mathrm{Be}_{25}, R_{c p} \approx 40 \pm 9 \mu \mathrm{m}$ for $\mathrm{Pd}_{43} \mathrm{Cu}_{27} \mathrm{Ni}_{10} \mathrm{P}_{20}$, and $R_{c p} \approx 430 \pm 20 \mu \mathrm{m}$ for $\mathrm{Pt}_{57.5} \mathrm{Cu}_{14.7} \mathrm{Ni}_{5.3} \mathrm{P}_{22.5}$, respectively. As $\rho>\rho_{c}, R_{p}$ continually increases. 
Figure 5 Critical shear offset as a function of notch radius. At the edge of the fractured surfaces of BMGs, a smooth region is observed. Such smooth region is a critical shear offset, $\lambda_{c}$, by shear banding across the sample. Microscopically, while approaching $\lambda_{c}$, it is envisioned that cavities grow by aggregation of interior microvoids which initiates fracture. (A) Representative shear offset patterns after fracture for $\mathrm{Pd}_{43} \mathrm{Cu}_{27} \mathrm{Ni}_{10} \mathrm{P}_{20}$ SENT samples with different radii, and $\lambda_{\mathrm{c}}$ is summarized in (C), which demonstrates that when $\rho \leq \rho_{c}, \lambda_{c}$ is essentially constant whereas for a larger radius, the shear offset scales directly with $\rho . Z_{44} \mathrm{Ti}_{11} \mathrm{Cu}_{10} \mathrm{Ni}_{10} \mathrm{Be}_{25}$ (B) and $\mathrm{Pt}_{57.5} \mathrm{Cu}_{14.7} \mathrm{Ni}_{5.3} \mathrm{P}_{22.5}$ (D) show a qualitatively similar behavior.

Figure 6 A schematic illustration of the mechanistic origin of a flaw tolerance behavior of BMGs. (A) Evolution of the local stress $\left(\sigma_{y y}\right)$ distribution and the plastic zone development ahead of the notch upon loading. First, a SENT sample undergoes elastic deformation upon loading, represented by curve "A" ( $\sigma_{y y} \propto \frac{1}{\sqrt{r}}, r$ is distance to notch tip). Curve "B" represents yielding. At a stress level of curve "C", propagation of shear bands forms a plastic zone size of $R_{C}$. The extensive shear banding activities releases strain energy through shear offset and such offset causes blunting of crack tip and crack stably grows to a fracture process zone size of $F_{c}$. The local stress slope in the plastic zone, $\frac{d \sigma_{y y}}{d r}$, scales directly with $1 /(r+\rho)\left(\sigma_{\mathrm{yy}}=\sigma_{\mathrm{y}}[1+\ln (1+\right.$ $\left.\left.\left.\frac{r}{\rho}\right)\right][42]\right)$. Hence, the slope of the local stress drops with crack tip blunting. The operation of shear banding and crack tip blunting redistribute the stress configuration and reduce stress concentration ahead of the crack tip. Further load is therefore permitted until the crack tip cannot blunt further and a critical fracture process zone size of $F_{D}$ is reached at the plastic-elastic interface so that fracture results and an ultimate plastic zone size of $R_{D}$ is reached (curve "D"). (B) For $\rho<\rho_{c}$ (curve "1" or "2"), stress concentration ahead of the notches is higher. The inherent crack blunting capability blunts the notch tip to a certain level. The maximum stress at the 
plastic-elastic interface follows the dashed red lines until the crack blunting capability is exhausted when the characteristic fracture process zone size of $F_{c p}$ is attained and the characteristic plastic zone size of $R_{c p}$ is reached at fracture. For blunt notches with $\rho>\rho_{c}$, the stress concentration intensity is lower (representative curve "4" or "5"). The location of the fracture process zone size at the plastic-elastic interface that reaches the critical value upon loading is beyond $F_{c p}$. In this case, the fracture process zone is postponed to an increased distance of $F_{4}$ or $F_{5}$, and the plastic deformation are postponed to an increased distance of $R_{4}$ or $R_{5}$, larger than $R_{c p}$. This scenario is reflected in the observed continually increased plastic zone size with increasing $\rho$ (Fig. 4). 

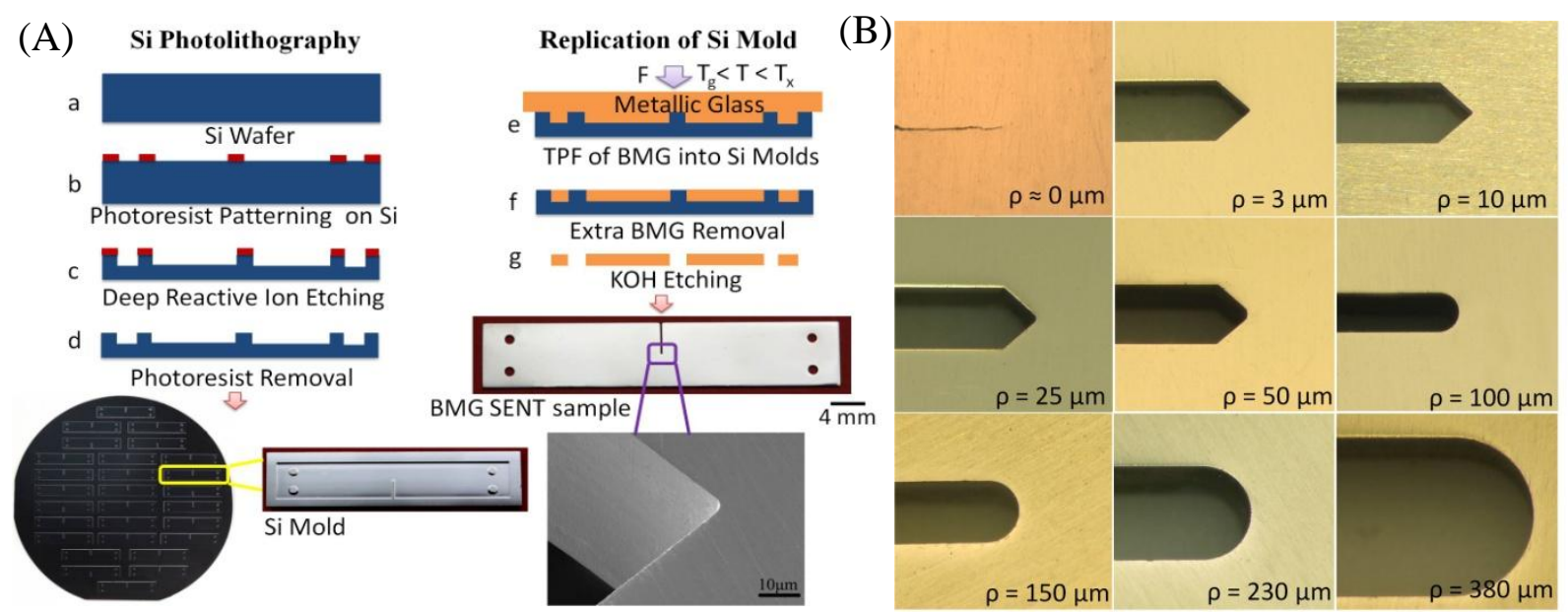

(C)

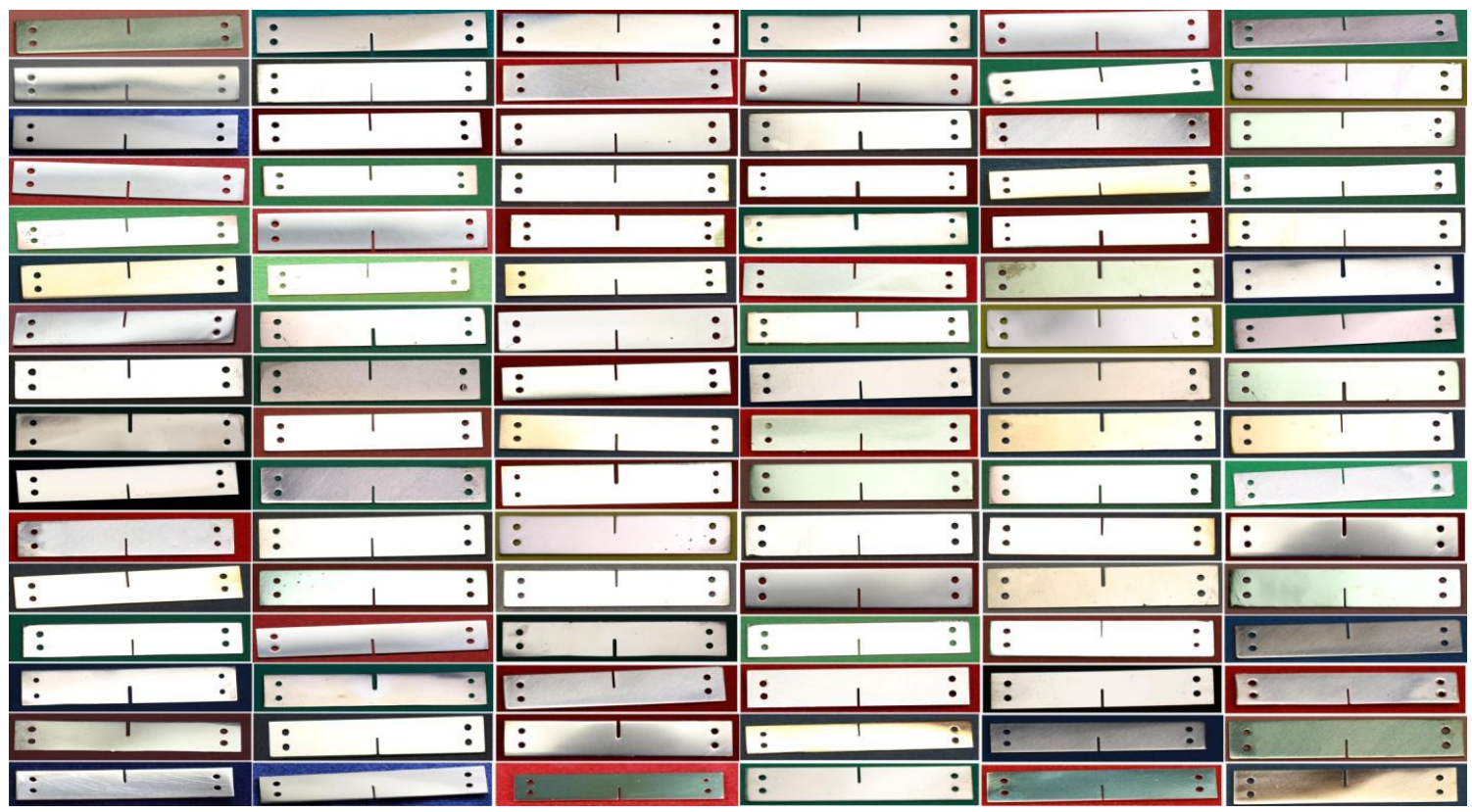

Figure 1 Chen W et al. 

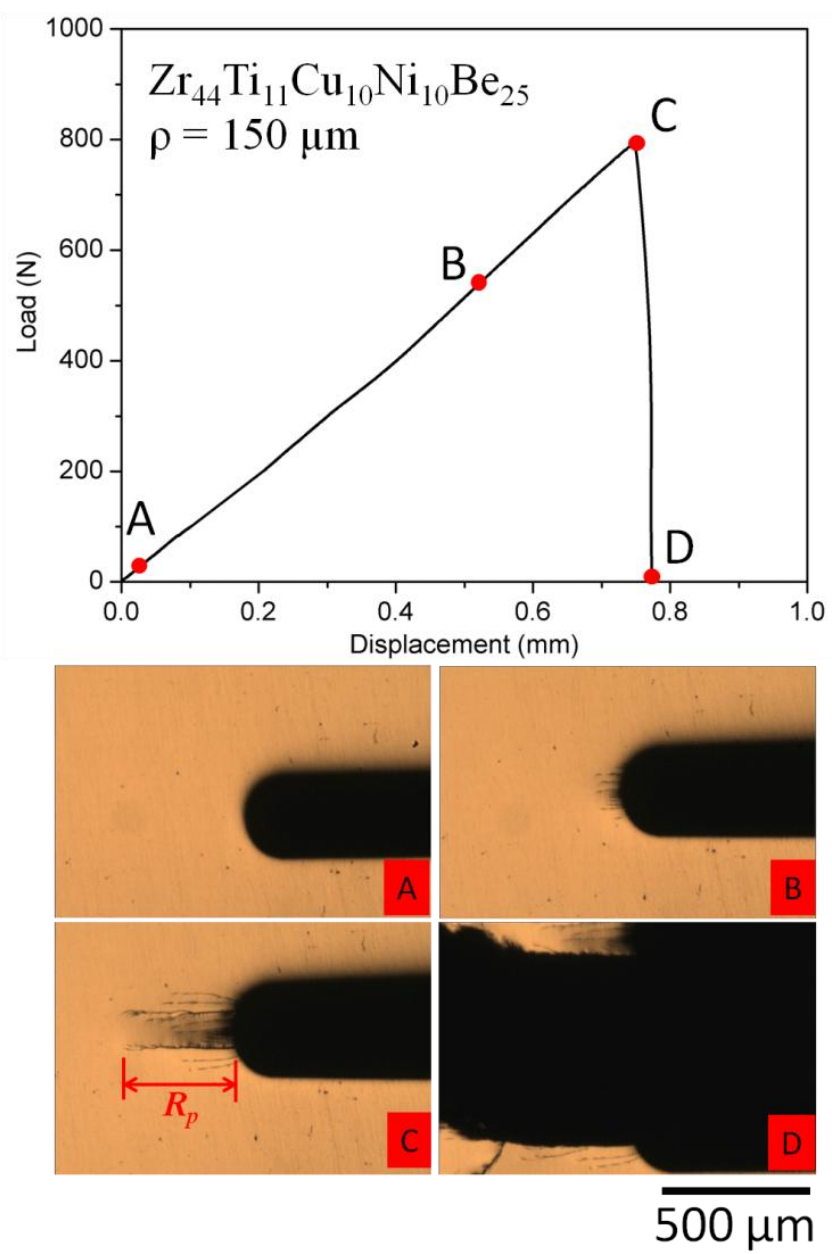

Figure 2 Chen W et al. 

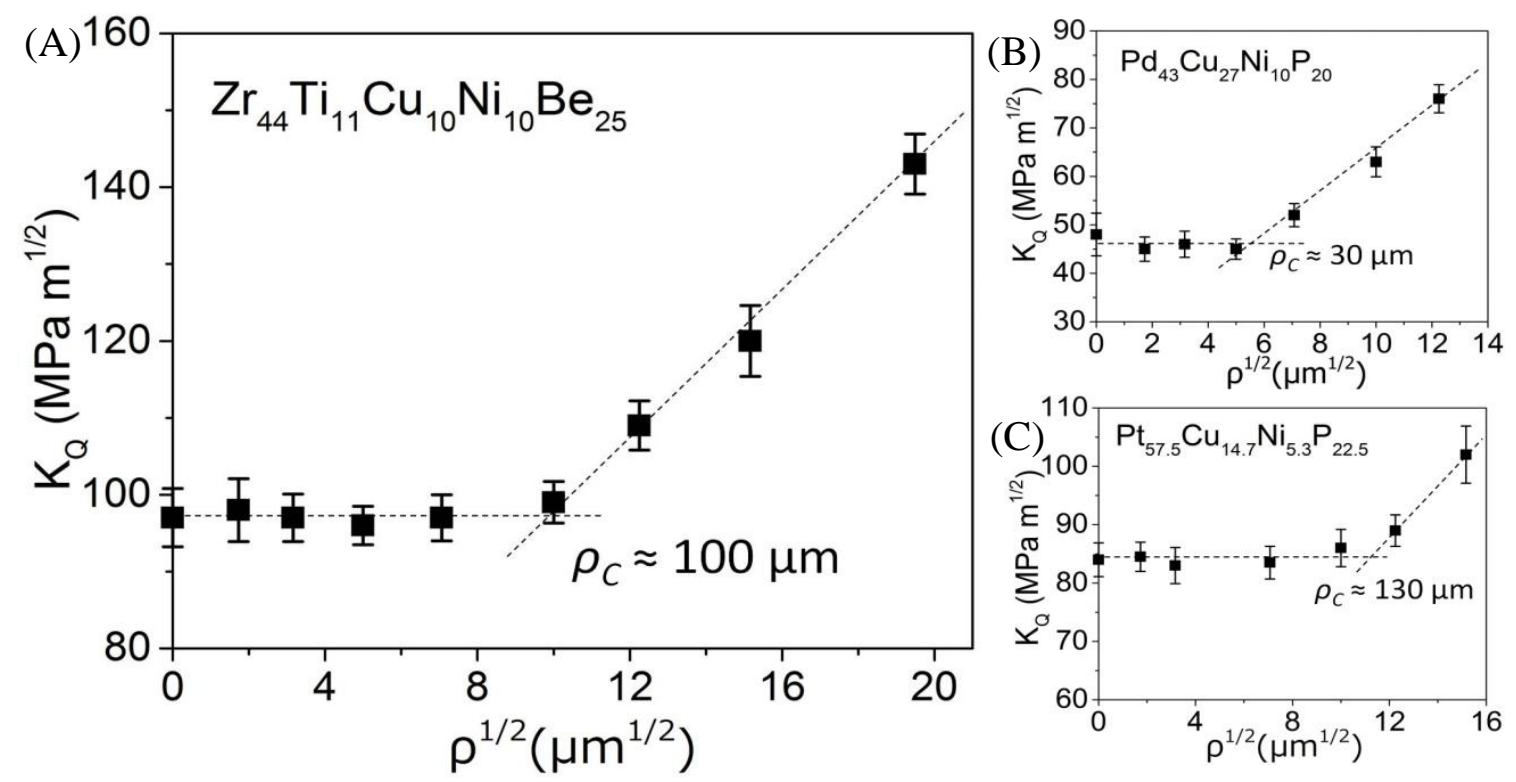

Figure 3 Chen W et al. 

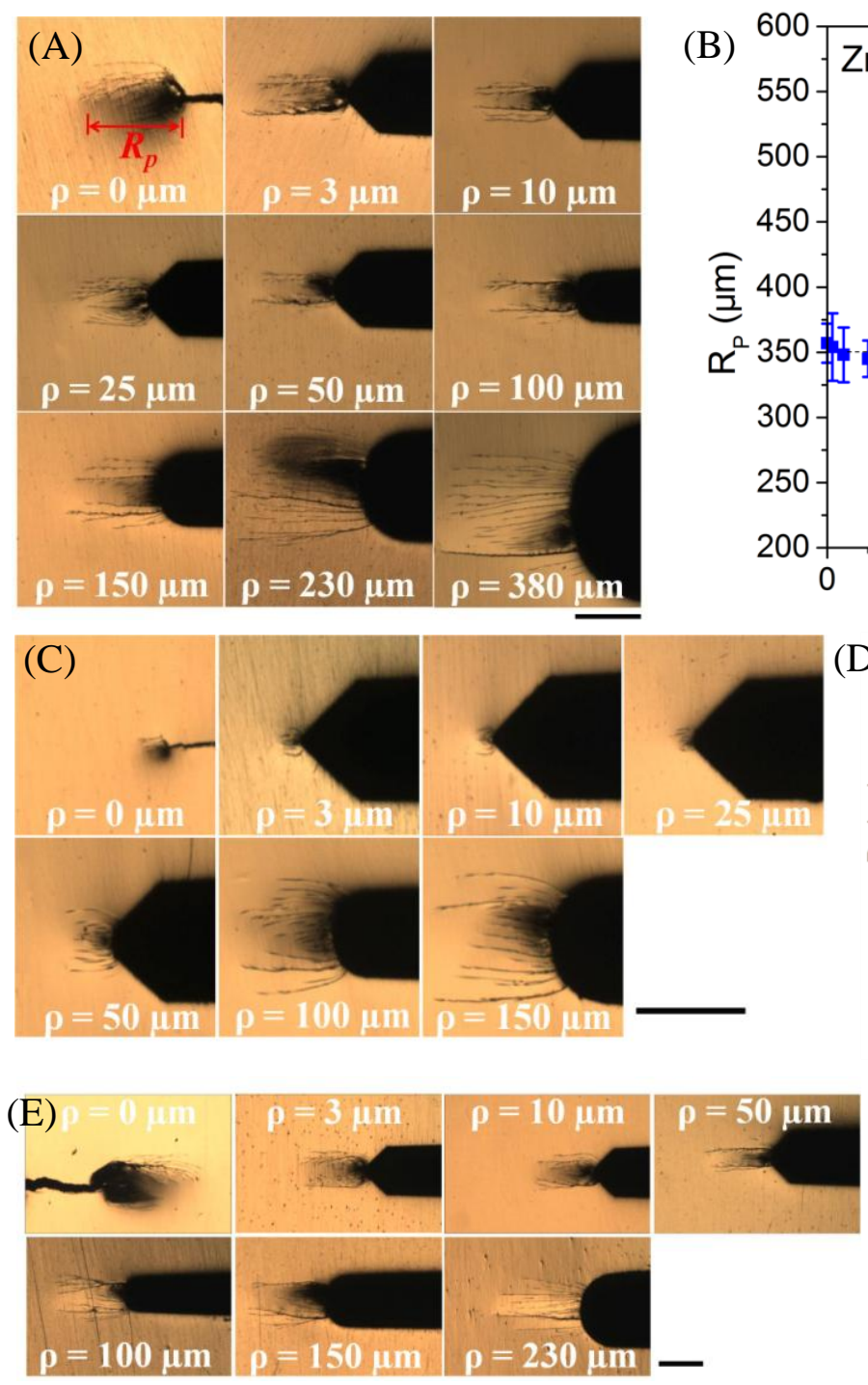

Figure 4 Chen $\mathrm{W}$ et al.
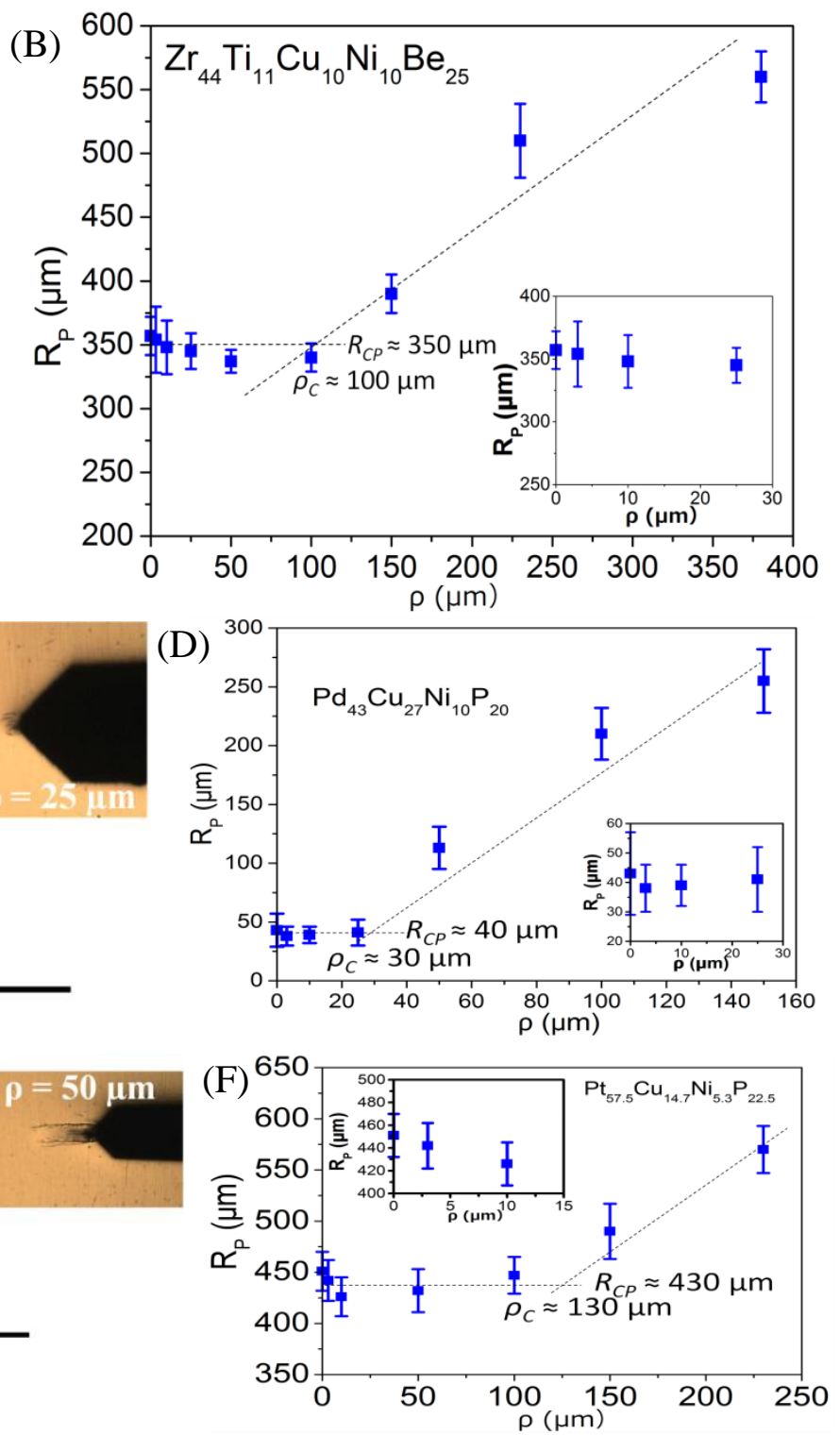

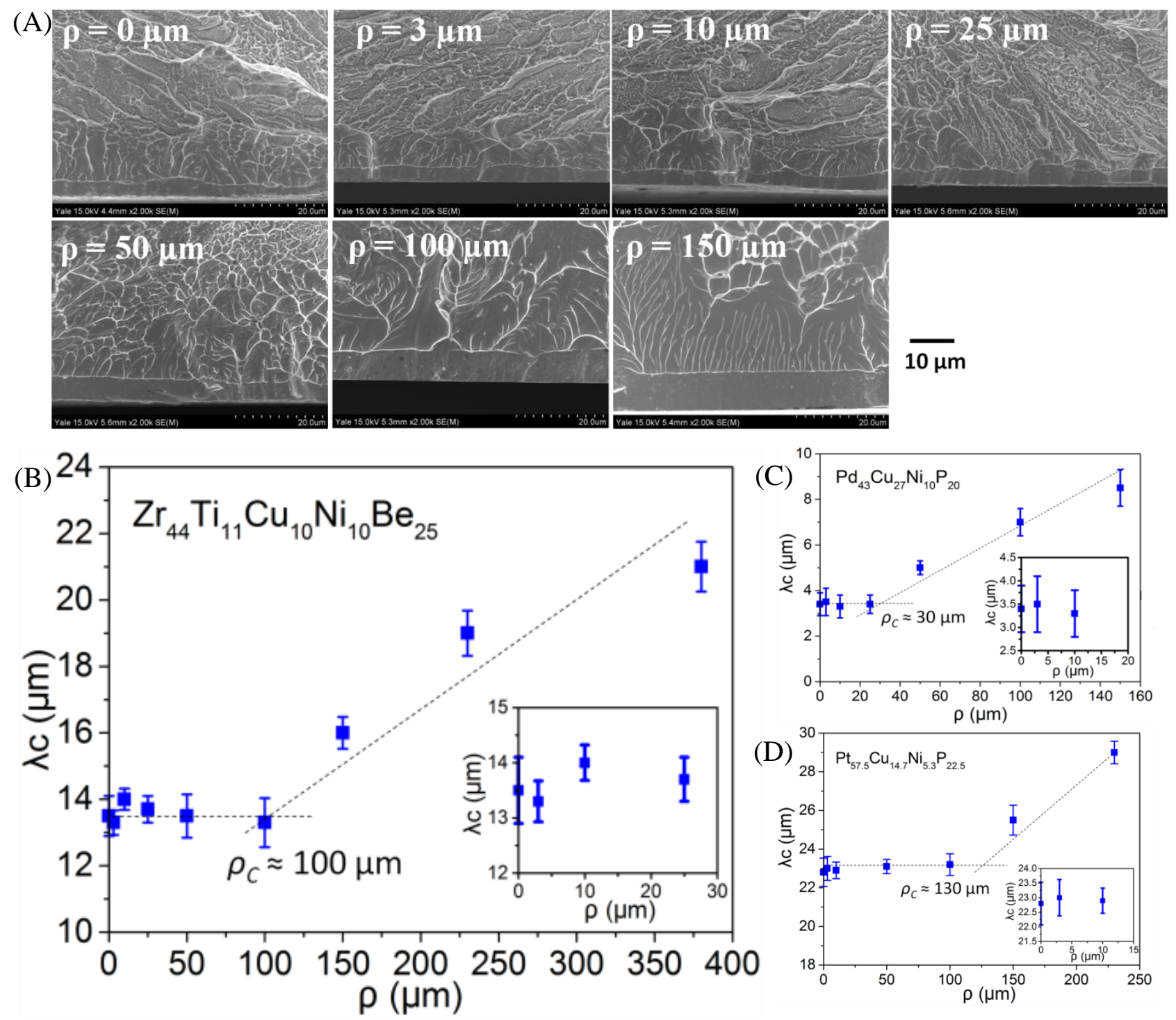

Figure 5 Chen W et al. 

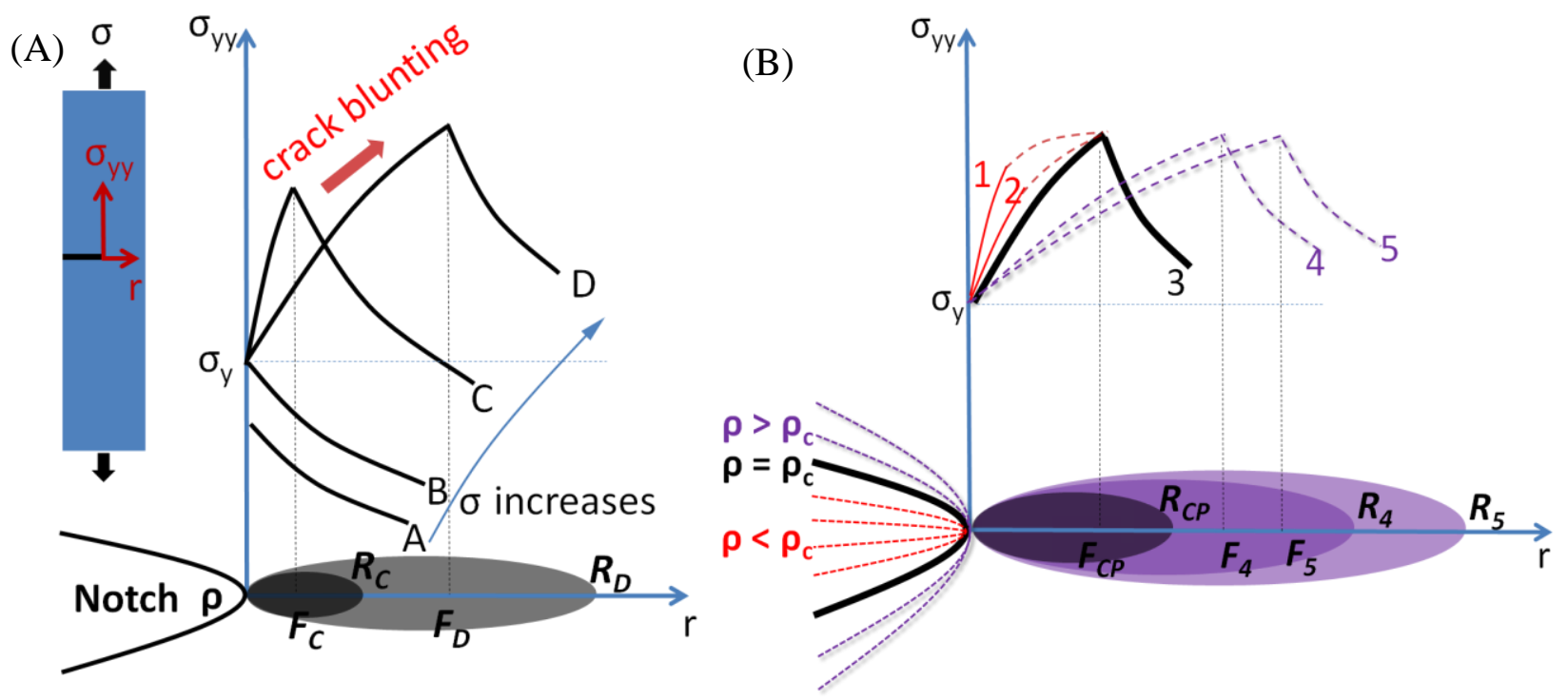

Figure 6 Chen W et al. 


\section{Graphical Abstract}

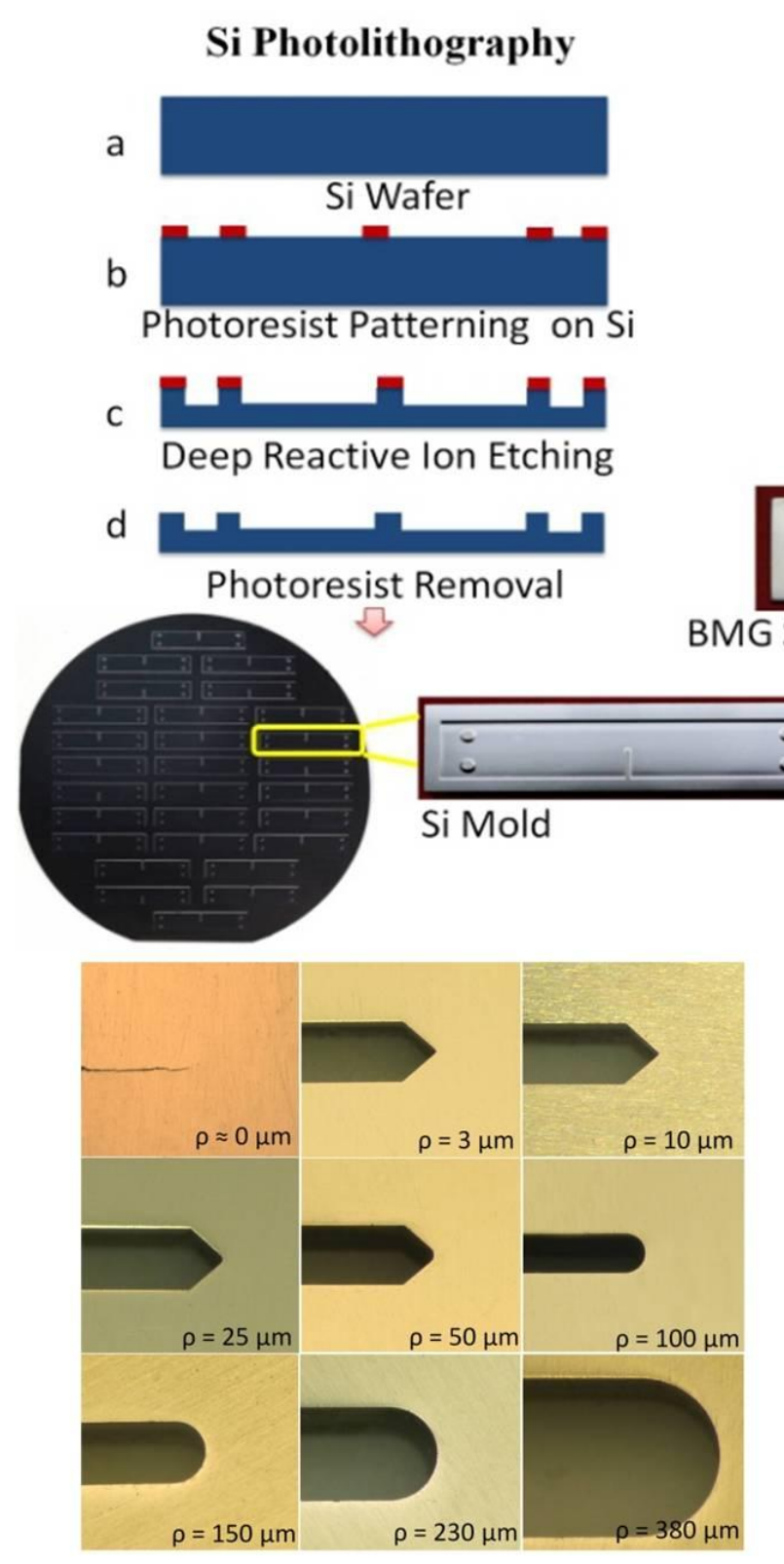

\section{Replication of Si Mold} $F \smile T_{g}<T<T_{x}$

e Metallic Glass TPF of BMG into Si Molds

f

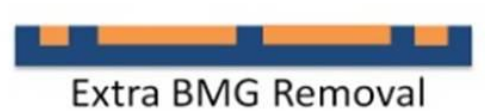

$\mathrm{g}=\frac{\mathrm{KOH} \text { Etching }}{=}$

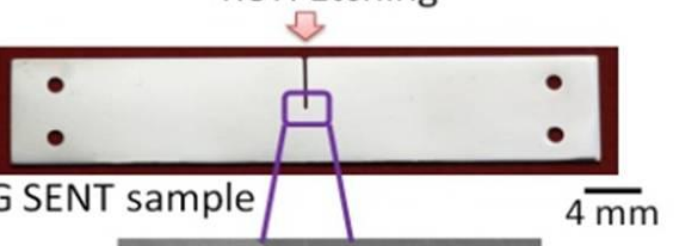

:
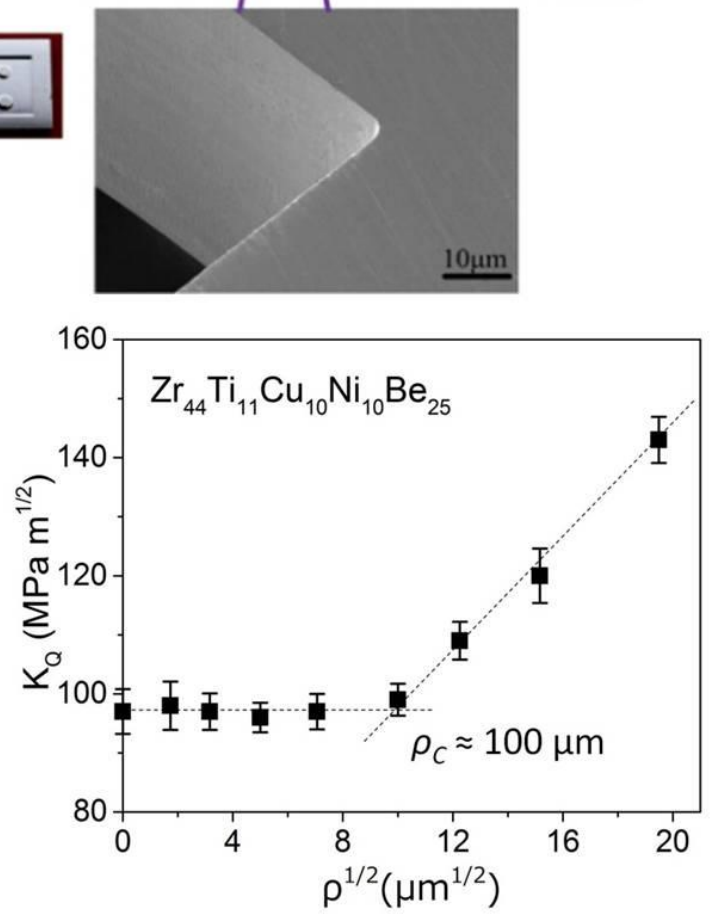